\title{
People Cannot Discover New Lands until They Have the Courage to Lose Sight of the Shore: Stress Echocardiography in Left Ventricular Outflow Obstruction
}

\author{
Giuseppe Barletta Maria Riccarda Del Bene
}

Diagnostic Cardiology, Careggi University Hospital, Florence, Italy
Dynamic left ventricular outflow tract obstruction (LVOTO) is the most important clinical feature of hypertrophic cardiomyopathy. LVOTO was the strongest predictor of all-cause death and sudden cardiac death [1]. However, LVOTO can be observed in several different clinical settings. In fact, LVOTO may be promoted by anatomical conditions such as the pattern of hypertrophy of the basal septum frequently observed in elderly hypertensive people, the angulated origin of the aorta, the calcification of the mitral annulus, the disproportionate length of the anterior mitral leaflet, and the malposition or hypertrophy of the papillary muscles. Further, the development of LVOTO may be facilitated by a small volume of the left ventricle, sometimes due to volume depletion or preload reduction.

In 1992, transient LVOTO was hypothesized to be the cause of hypotension in more than one-third of normal subjects during dobutamine stress echo [2]. LVOTO was described as occurring both because of a systolic anterior motion of the mitral valve and as a result of hyperdynamic contraction of the mid-ventricular (papillary muscles) and apical regions of the left ventricle inducing cavity obliteration. The hypothesis was a matter of debate, and alternatively LVOTO was mainly related to higher baseline blood pressure [3].

In the same year, a relationship between dobutamineinduced dynamic mid-ventricular obstruction and chest

karger@karger.com

(c) 2021 S. Karger AG, Basel

www.karger.com/crd

Karger" pain was suggested [4]. Two studies [5, 6] showed an excellent prognosis and beneficial effects of $\beta$-blocker therapy on symptoms in these subjects over a 2 -year followup.

The review "Usefulness of stress echocardiography in assessment of dynamic left ventricular obstructions; case series and review of the literature" is an update on LVOTO in the work-up for effort angina or angina-equivalent symptoms [7].

Today, coronary CTA is the recommended first-line examination for patients with chest pain and low clinical likelihood of obstructive CAD. Noninvasive functional imaging to demonstrate myocardial ischemia is recommended in intermediate clinical likelihood of obstructive CAD [8].

In symptomatic patients in whom coronary CTA did not show an obstructive CAD, the reason for symptoms remains unexplained if no other diagnostic tests are performed. Saeed and Vegsundvåg are to be commended for showing the usefulness of the different technical options offered by echocardiography to give evidence of LVOTO as the possible cause for symptoms, and guide therapeutic decision making. In fact, $\beta$-blockers were demonstrated

Giuseppe Barletta and Maria Riccarda Del Bene contributed equally to this work. 
to be beneficial on symptoms and improve the quality of life.

Besides pre-existing anatomical and/or functional hemodynamic conditions, the role of catecholamine stimulation is intriguing in the scenario of LVOTO. In fact, a surge of catecholamines eliciting the LVOTO is the common denominator that several clinical situations, such as takotsubo syndrome, shock syndrome, anemic shock, and acute coronary syndromes, may have [9]. In its turn, LVOTO has to be regarded as the common final response of the left heart to different pathophysiological pathways. Symptomatic patients with LVOTO during dobutamine stress echocardiography did not have a greater incidence of takotsubo syndrome [10], nor an abnormal sympatovagal balance [11]. Dobutamine stress test may induce LVOTO in patients with previous takotsubo, but it does not reproduce the morpho-functional features of the syndrome [12] at variance with cold pressor stress [13].

The current understanding of cardiac dynamics relies on the myocardial band concept, whereby the architecture of myocardial fibers differs among LV regions, implying different dynamic contributions to the development of the ejection upon contraction. The development of LVOTO suggests that catecholamines overstimulate the contraction of the basal and mid-ventricular myocardium with respect to the apical myocardium. Such a pattern of contraction differs from what the myocardial band concept predicts for the spiral fibers whose contraction shortens the longitudinal length of the left ventricle and increases its circumferential thickening. More studies are needed to verify the hypothesis of a relationship between the response to catecholamines and the architecture of the myocardial fibers, perhaps in the scenario of an excess of regional cardiac catecholamine release/response. Alternative hypotheses to explain the increased response of the basal regions of the left ventricle are (1) the development of excessive LV afterload due to LVOTO and (2) an increase in wall stress, where myocardial curvature is greater with microvascular dysfunction and impaired perfusion [14].

What we know today is that LVOTO is the consequence of a pre-existent anatomical condition or a transient functional event due to hemodynamic changes. The finely tuned mechanisms behind its genesis and the link with symptoms remain a puzzle.

\section{Conflict of Interest Statement}

The authors have no conflicts of interest to declare.

\section{Funding Sources}

The authors did not receive any funding.

\section{References}

1 Liu Q, Li D, Berger AE, Johns RA, Gao L. Survival and prognostic factors in hypertrophic cardiomyopathy: a meta-analysis. Sci Rep. 2017 Sep 20;7(1):11957.

2 Pellikka PA, Oh JK, Bailey KR, Nichols BA, Monahan KH, Tajik AJ. Dynamic intraventricular obstruction during dobutamine stress echocardiography. A new observation. Circulation. 1992 Nov;86(5):1429-32.

3 Heinle SK, Tice FD, Kisslo J. Hypotension during dobutamine stress echocardiography: is it related to dynamic intraventricular obstruction? Am Heart J. 1995 Aug;130(2):3147.

4 Murakami H, Nishimura M, Urabe K. Relation between dynamic midventricular obstruction and unexplained chest pain in patients with normal echocardiograms at rest. Am J Cardiol. 1996 Nov 1;78(9):1063-5

5 Secknus MA, Niedermaier ON, Lauer MS, Marwick TH. Diagnostic and prognostic implications of left ventricular cavity obliteration response to dobutamine echocardiography. Am J Cardiol. 1998 Jun 1;81(11):131822.
6 Cabrera-Bueno FJ, Gómez-Doblas JJ, GarciaPinilla JM, Montiel-Trujillo A, Jiménez-Navarro M, Martinez-Del-Valle D, et al. Dobutamine stress echocardiography identifies patients with angina and dynamic left ventricular outflow obstruction in physiological exercise. Echocardiography. 2009 Mar; 26(3):272-80.

7 Saeed S, Vegsundvåg J. Usefulness of stress echocardiography in assessment of dynamic left ventricular obstructions; case series and review of the literature. Cardiology. 2021;110.

8 Knuuti J, Wijns W, Saraste A, Capodanno D, Barbato E, Funck-Brentano C, et al. ESC guidelines for the diagnosis and management of chronic coronary syndromes. Eur Heart J. 2020 Jan 14;41(3):407-77.

9 Redfors B, Shao Y, Ali A, Omerovic E. Current hypotheses regarding the pathophysiology behind the takotsubo syndrome. Int J Cardiol. 2014 Dec 20;177(3):771-9.
10 Singh A, Sturzoiu T, Vallabhaneni S, Shirani J. Stress cardiomyopathy induced during dobutamine stress echocardiography. Int J Crit Illn Inj Sci. 2020 Sep;10(Suppl 1):43-8.

11 Barletta G. Dobutamine-inducible left ventricular obstruction: head-up tilt and autonomic balance. Int J Cardiol. 2003 Feb;87(23):245-52.

12 Previtali M, Camporotondo R, Repetto A, Panigada S. Dobutamine stress echocardiography for assessing the role of dynamic intraventricular obstruction in left ventricular ballooning syndrome. Cardiovasc Ultrasound. 2010 Apr 9;8:11.

13 Barletta G, Del Pace S, Boddi M, Del Bene R, Salvadori C, Bellandi B, et al. Abnormal coronary reserve and left ventricular wall motion during cold pressor test in patients with previous left ventricular ballooning syndrome. Eur Heart J. 2009 Dec;30(24):3007-14.

14 El Mahmoud R, Mansencal N, Pilliére R, Leyer F, Abbou N, Michaud P, et al. Prevalence and characteristics of left ventricular outflow tract obstruction in Tako-Tsubo syndrome. Am Heart J. 2008 Sep;156(3):543-8. 